\title{
The Interaction Effect of Comprehensiveness Between Social Media and Online Purchasing Intention in Jordanian Pharmacies
}

\author{
https://doi.org/10.3991/ijim.v14i15.15501 \\ Jassim Ahmad Al-Gasawneh ${ }^{(凶)}$ \\ Applied Science Private University (ASU), Amman, Jordan \\ jassemghasawneh@yahoo.com \\ Mahmoud Hussein Al-Wadi \\ Middle East University, Amman, Jordan \\ Belal Mahmoud Al Wadi \\ LEVENBERT for Studies and consulting, Muscat, Sultanate of Oman \\ Bandar Ersan Alown \\ University Sultan Zainal Abidin, Kampung Gong Badak, Malaysia \\ Nawras M Nuseirat \\ Applied Science Private University (ASU), Amman, Jordan
}

\begin{abstract}
This empirical paper examined the moderating role of comprehensiveness between social media and online shopping intention among customers of Jordanian pharmacies. Technology acceptance model (TAM) and theory of planned behavior (TPB) were the applied theories in this study. Data were collected from potential customers using survey questionnaire. A total of 198 usable questionnaires were obtained and the data were analyzed. Partial least squares structural equation modeling (PLS-SEM) was used in the outcome examination. The results show a positive impact of social media on online shopping intention Further, comprehensiveness moderated the relationship strengths between social media and online shopping intention. This paper finds that focusing on social media strategies such as adopting intimacy, decreasing the perceived risk, and increasing trust could motivate online shopping among customers. Pharmacies in Jordan may consider these findings and achieve them by providing more comprehensive information in their advertisement and announcement.
\end{abstract}

Keywords-Social media, comprehensiveness, online shopping Intention, Jordan, pharmacies.

\section{$1 \quad$ Introduction}

Online shopping is the preferred shopping mode among many consumers at present time, and at the global level, the Internet is an important tool for communication and 
business [1]. As reported in [2], in 2019, the internet users amounted to more than four billion and this amount signified 1,157\% growth since 2000. In 2018, [2] reported that globally, about 1.8 billion people bought goods online, and during the same year, the Internet had generated $\$ 2.8$ tn worth of sales. By 2021, the amount is expected to reach \$4.8tn [2], implying the potential drastic increase of online shopping [3]. Accordingly, by way of emails, social media, or other internet tools, the conventional business is changed into online shopping [4], [5].

In the context of Jordan, online shopping is becoming common [6]. In fact, businesses in this country have started to apply the e-commerce business models and sell their products online. Somehow, according to [7], compared to its neighbors such as those in the gulf region, both E-commerce and online shopping in Jordan, which is a developing economy in the Middle East region, is still weak. Furthermore, online shopping in Jordan was very low during the early stage as the consumers were reluctant owing to their lack of knowledge in internet shopping [8]. There was also a lack of knowledge concerning the behavior of consumers towards this new shopping mode [8], in addition to the presence of risks linked to this new shopping mode [9], [10], [11].

The use of social media allows businesses to be strongly connected to the targeted audience and capture their attention, which in turn can motivate them to make the purchase using the internet sites [12]. As such, social media should be included in the company's marketing budget [12]. Relevantly, [13] and [14] mentioned comprehensiveness in the information and advertainment as among the key factors impacting the adoption of online shopping. As appositely highlighted by [15], comprehensiveness of the applied solution can effectively reach the end recipient on social media, as it allows users to actively gain access to resources and information. Therefore, the current study attempts to investigate the moderating role of comprehensiveness on the relationship between social media and online shopping intention.

\section{Literature Review}

\subsection{Online shopping intention}

Next to email and Web surfing, [16] reported online purchase as the third most popular activity that involves the use of the Internet. The popularity of online purchase has in fact significantly increased after the birth of e-commerce. [17] indicated that online purchase starts with purchase intention. which, as described by [18] and [19], entails the willingness of customers to make purchase through the internet. As described in [20] and [21], consumers' willingness to buy a given product or service via the internet stores is online purchase intention. [17] also discussed the concept of online purchase intention in their study by describing it as the intention of online shoppers in purchasing certain goods and services using the medium of the Internet or virtual shopping carts. In another relevant study by [22] online purchase intention was described as the willingness of customers in utilizing the internet services to perform an actual purchase of goods and services or to compare product prices. 
Consumer behavior is predictable through their purchase intention. Meanwhile, purchase intention is affected by several factors, and therefore, measuring consumer behavior is a very challenging task. Furthermore, the use of privacy and security statements can increase online purchase intention [23]. It should also be noted that in influencing purchase intentions of consumers; trust of customer towards the competency of company in meeting both their needs and wants is beyond mere goodwill trust. Nonetheless, the use of purchase intention as a measure in the prediction of customers' real activities of purchase is common among scholars.

In the present study, online shopping intention is determined and measured using the following: probability of online product purchase, probability of recommending online shopping to others and probability of making another online purchase if the purchased products are found beneficial. The present study follows that of [24].

\subsection{Social media}

Social media is now a major networking and marketing platform for an increasing number of e-commerce ventures. For instance, Instagram and Facebook, as among the common social media, are responsive towards the fundamental need of man to socially interact. Social media furnish people with a space that allows them to communicate, share ideas and create common values [25].

Within the context of behavioral motivation, social interaction plays a significant role. As explained in social interaction theory, the access to a significant number of users of social commerce network, not their centrality within that network, benefits seller to a significant level [26], [27]. [28] relevantly discussed the phenomenon of clustering in their study by stating that members of a community are impacted by the proximity of their friends and the behavior and character of those friends as well. Such clustering transforms their behavior as consumer. As indicated in [29], the transformation can equally be impacted by the nature of the retail platform itself.

In research that involve psychological factors and mechanisms that majorly affect customer purchasing intentions in e-commerce, perceptions of risk and trust have been regarded as key constructs. Conversely, studies in the social interaction domain have not been prioritizing these constructs. Also, customer perceptions and how this construct impacts buying intentions have not been sufficiently explored. Meanwhile, in social commerce setting, word-of-mouth has proven to be a very effective mechanism of marketing. Here, much of the content is produced by user. Accordingly, affinity between users in interactive information sharing, such as in user feedback and recommendations, leads to the acceptance of users of the generated contents. [30] relevantly indicated that the stronger the affinity, the more frequent the interaction, as can be observed among individuals with close relationships, such as the interactions between friends and family members.

Intimacy: Intimacy encompasses a measure of the degree of closeness of a given relationship, and it considers emotional ties and a sense of spiritual association and approval [31]. In the present study, intimacy is described as an emotional connection 
between user and commercial promoter in social media, taking into account the interactivity levels and the nature of the psychological connection between both parties (user and commercial promoter).

Perceived risk: Perceived risk can be described as a measure of the level to which uncertainty affects the process of decision-making. Within the context of online shopping, [31] found that it is not always possible to accurately predict the transaction outcome. In other words, online shopping customers is always obliged to take a risk.

Trust: In [31], the construct of trust was defined as a cooperative relationship, in which one party is sufficiently confident that the other party is not only reliable but honest as well. Following this delineation, the present study defines the construct of trust as the confidence level that is present among customers concerning other users and concerning the online shopping platform itself.

Three elements recommended by [31] are included in the analysis. These elements are as follows: a) emotional intimacy level between the consumer and the promoter which is established via the channels of social media; b) the projected risks relating to online purchase; and c) the formed trust level between user and product marketer.

\subsection{Comprehensiveness}

Comprehensiveness was described in [13] as the level to which customer images are complete and adequate to meet the needs of customers. Relevantly in their study, [14] indicated that combined with relevance, comprehensiveness becomes a key factor that impacts the adoption of information.

Comprehensiveness relates to the wholeness of the conveyed message. It was accordingly mentioned in [32] that within the context of online customer review, the presence of information with greater details brings a broader breadth of user categories and user orientation. This will increase the possibility of user acquisition and user retention. Also, messages in greater details will increase the comprehension of customers, which will in turn satisfy their awareness of the given product or services. Equally, it is important to provide message with comprehensiveness because messages that are incomplete can lead to different interpretations among customers.

In this study, the delineation of the construct of comprehensiveness is based on the works of [14] and [32]. Hence, comprehensiveness of message within the context of this study is described as messages that are complete and adequate, include all the values needed, satisfy the needs of customer, and are adequate in terms of breadth and width.

\subsection{The relationship between research variables}

Social media has been found to have positive and significant impact on online shopping intention in a number of studies including [33]. [34] relevantly reported that via bloggers, social media imparts positive impact on Online shopping Intention. Additionally, [35] reported in their study that the utilization of Social Media imparted a positive and significant impact on Online Shopping. Conversely, the negative impact of social media was discussed in [36] and [37] owing to the issues of security that can decrease 
the intent of customer in engaging in online shopping. In another related study. [38] indicated the occasional adverse response from customers towards social media platforms, which means that these platforms also negative impact customer's engagements.

Also, comprehensiveness was found to impact social media and online shopping intention, as reported in several studies including [13], [14], [15]. Accordingly, considering the inconclusive findings of past extant studies, and in agreement with the proposition brought forth in [39], [40] and [41], a moderating variable should be included if the relationship between the predictors and the dependent variables appears to be inconsistent. The present study will therefore include the construct of comprehensiveness as moderator between social media and online shopping intention. As such, considering the above discussion, this study presents the following hypotheses:

- H1: Social media has a positive impact on Online shopping intention

- H2: Comprehensiveness moderates the relationship between social media and online shopping intention.

\section{Methodology}

As a descriptive study, the present study attempts to present a description of the related conditions and phenomena. In particular, this study presents a description of the present situation, followed by a process of decision making. This brings to the formulation of several hypotheses and these hypotheses are then tested. For data gathering purposes, this study utilizes self-administrated questionnaires. These questionnaires were distributed to customers of pharmacies in Jordan. All of the customers were at least 22 years old; customers in this age category were chosen because they generally understand what product purchase is and they also can decide on the item to purchase from the existing choices. Owing the ability of these customers in making purchase decision, the present study employed a convenience sampling technique in choosing the study samples.

As mentioned, questionnaire was employed in this study to gather the data. In this study, the used questionnaire was split into four sections as follows: The first section comprises items related to personal and demographic information of the respondents including age, gender, status and education; the second section presents items based on the models proposed by [31] and [41] namely items on social media use, focusing on three areas namely trust (five items), perceived risk (four items) and intimacy (three items), and items in Section 2 were furnished with 5-point Likert scale each; the third section comprises four items on comprehensiveness as in [14], the fourth section comprises three items associated with online shopping intention based on [24].

In order to assure that each item fulfils the study's specific purposes, modifications were made to the questionnaire items as needed. Also, in order to assure validity of the items, external academics were asked to review them. Then, the internal consistency of the items was evaluated by determining the variables' Cronbach's Alpha. The obtained results of the Cronbach's Alpha were as follows: perceived risk $=0.77$; intimacy $=0.72$; trust $=71$; comprehensiveness $=0.84$; and online shopping intention $=0.83$. All of the attained values affirmed the reliability and validity of the questionnaire. 
Additionally, the sample size must conform to the power of analysis; based on the model's complexity, the minimum sample size for the study was determined. In this study, the determined minimum sample size was 68, as proposed in [42] table; two predictors from the research framework were included, with medium effect [43]. Relevantly, [44] proposed that a sample size should be bigger than 100 in order to assure accurateness. Hence, this study distributed a total of 300 questionnaires to the respondents. Meanwhile, the model of the study was analyzed using the partial least squares method run using the Smart PLS 3.0 software.

\section{Result}

A total of 230 questionnaires were returned. From this amount, 32 were incomplete. Hence, 198 questionnaires were usable for analysis.

\subsection{Moderating analysis approach}

The partial least squares method was used in the data analysis, by way of two-stage method for moderator analysis. Here, the existing reflective constructs and indicators were used, whereby the problems related to the product indicator approach's weak statistical power, were eliminated. Specifically, the first stage involves the determination of the convergent validity and discriminant validity (with the exception of the interaction term) (see Figure 1), while the second stage involves dealing with the structural model requirements (see Figure 3). Based on [45] and [41], product indicator associated with the second-stage analysis was computed, leading to the interaction term alongside the predictor and moderator variables.

\subsection{Measurement model}

In this study, there are three major variables as follows: Comprehensiveness (firstorder construct), online shopping (first-order construct), and social media (second-order construct). The evaluation of social media involved the use of three factors. In this study, social media interaction was classed as a second-order reflective construct. Meanwhile, trust, intimacy and perceived risk were the first-order constructs, and these constructs provide reflective measurements relating to the reflective-reflexive type. In this study, social media was an appropriate treatment for second-order element. This will enrich the understanding of its conceptual and consensus aspects. Additionally, the second order was utilized in reducing the quantity of relationships, and also the quantity of hypotheses to be addressed in the structural model. According to [46], such utilization allows the PLS path model to be easily interpreted.

The present study utilized the two-stage approach as proposed in [47]. As such, during the first stage, this study utilized the repeated indicator approach. Here, the firstorder scores were collected for first-order constructs, and during the second stage, the weighting of the first-order variables was utilized in the computation of the secondorder contract's CR and AVE. 
Convergent validity and discriminant validity were used in this study in the evaluation of the measurement model. The convergent validity evaluation includes the analysis of the following: composite reliability, average variance extract (AVE) and factor loading. Accordingly, the following Figure 1 and Table 1 display the results. As can be seen, each item's loading was greater than 0.5; AVE figures were greater than 0.5 and CR figures were greater than 0.7.

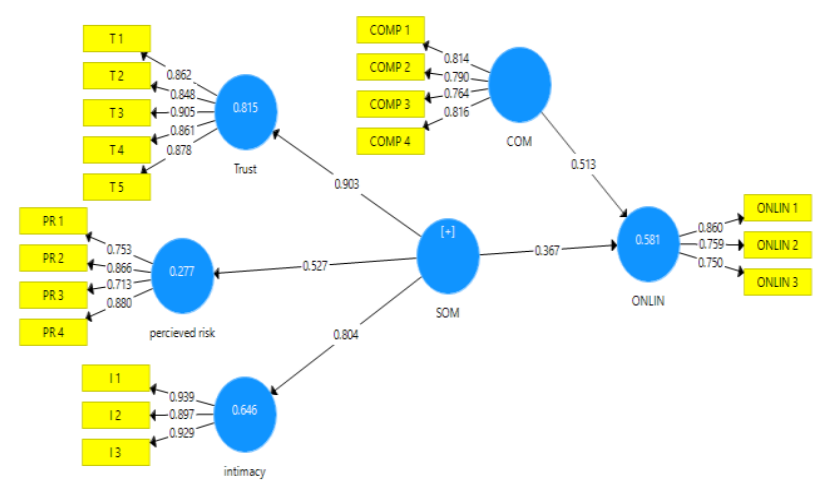

Fig. 1. The Measurement Model

Table 1. Measurement model

\begin{tabular}{|c|c|c|c|c|}
\hline First order Construct & Items & Factor loading & $\mathbf{C R}$ & AVE \\
\hline \multirow[t]{4}{*}{ Comp } & COMP 1 & 0.814 & 0.874 & 0.634 \\
\hline & COMP 2 & 0.790 & & \\
\hline & COMP 3 & 0.764 & & \\
\hline & COMP 4 & 0.816 & & \\
\hline \multirow[t]{3}{*}{ Online } & ONLINE 1 & 0.860 & 0.833 & 0.626 \\
\hline & ONLINE 2 & 0.759 & & \\
\hline & ONLINE 3 & 0.750 & & \\
\hline \multirow[t]{4}{*}{ Perceived risk } & PR 1 & 0.753 & 0.881 & 0.650 \\
\hline & PR 2 & 0.866 & & \\
\hline & PR 3 & 0.713 & & \\
\hline & PR 4 & 0.880 & & \\
\hline \multirow[t]{3}{*}{ Intimacy } & IN 1 & 0.939 & 0.944 & 0.849 \\
\hline & IN 2 & 0.897 & & \\
\hline & IN 3 & 0.929 & & \\
\hline \multirow[t]{5}{*}{ Trust } & T 1 & 0.862 & 0.940 & 0.759 \\
\hline & $\mathrm{T} 2$ & 0.848 & & \\
\hline & T 3 & 0.905 & & \\
\hline & $\mathrm{T} 4$ & 0.861 & & \\
\hline & T 5 & 0.878 & & \\
\hline \multicolumn{5}{|l|}{ Second order contract } \\
\hline \multirow[t]{3}{*}{ SOM } & PR & 0.527 & 0.798 & 0.580 \\
\hline & IN & 0.804 & & \\
\hline & $\mathrm{T}$ & 0.903 & & \\
\hline
\end{tabular}


HTMT measures the model's discriminant validity [48], and in this study, the obtained HTMT construct values were below 0.90, in particular, they fell in the range between 0.325 and 0.887 . The results are displayed in Table 3. Hence, based on [48] each latent construct measurement in this study was exclusively discriminant against each of the others.

Table 2. Discriminant validity (HTMT)

\begin{tabular}{|l|c|c|c|c|c|c|}
\hline & COMP & ONLIN & SOM & TRUST & INTIMACY & PERCIEVED RISK \\
\hline COMP & & & & & & \\
\hline ONLIN & 0.887 & & & & & \\
\hline SOM & 0.671 & 0.713 & & & & \\
\hline TRUST & 0.357 & 0.573 & 0.826 & & & \\
\hline INTIMACY & 0.325 & 0.562 & 0.755 & 0.654 & & \\
\hline $\begin{array}{l}\text { PERCIEVED } \\
\text { RISK }\end{array}$ & 0.855 & 0.762 & 0.728 & 0.387 & 0.334 & \\
\hline
\end{tabular}

In the evaluation of the constructs and their relative items in the CFA model, the convergent validity and the discriminant validity analysis results for the measurement model show the appropriateness and accurateness of the measurement scale. Accordingly, the analysis results for convergent validity and discriminant validity are respectively displayed in Table 1 and Table 2.

\subsection{Structural model}

As suggested by [46] this study evaluated the structural model, R2, beta, t-values via bootstrapping with a 1,000 resample, the predictive relevance (Q2), and VIF. The evaluation of social media interaction was carried on the second-order construct (refer Figure 2- Figure3).

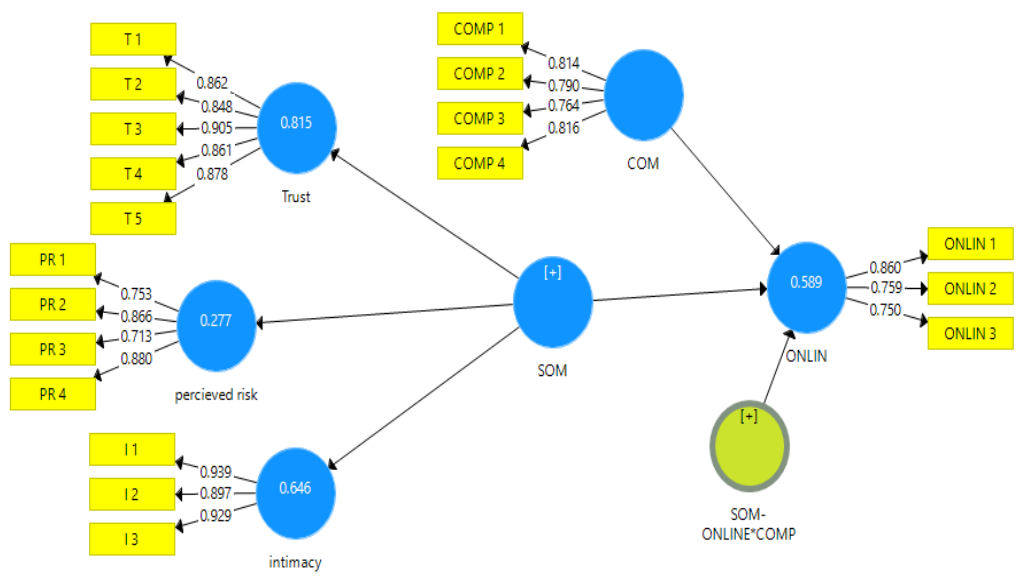

Fig. 2. $R^{2}$ after integrated interaction effect 


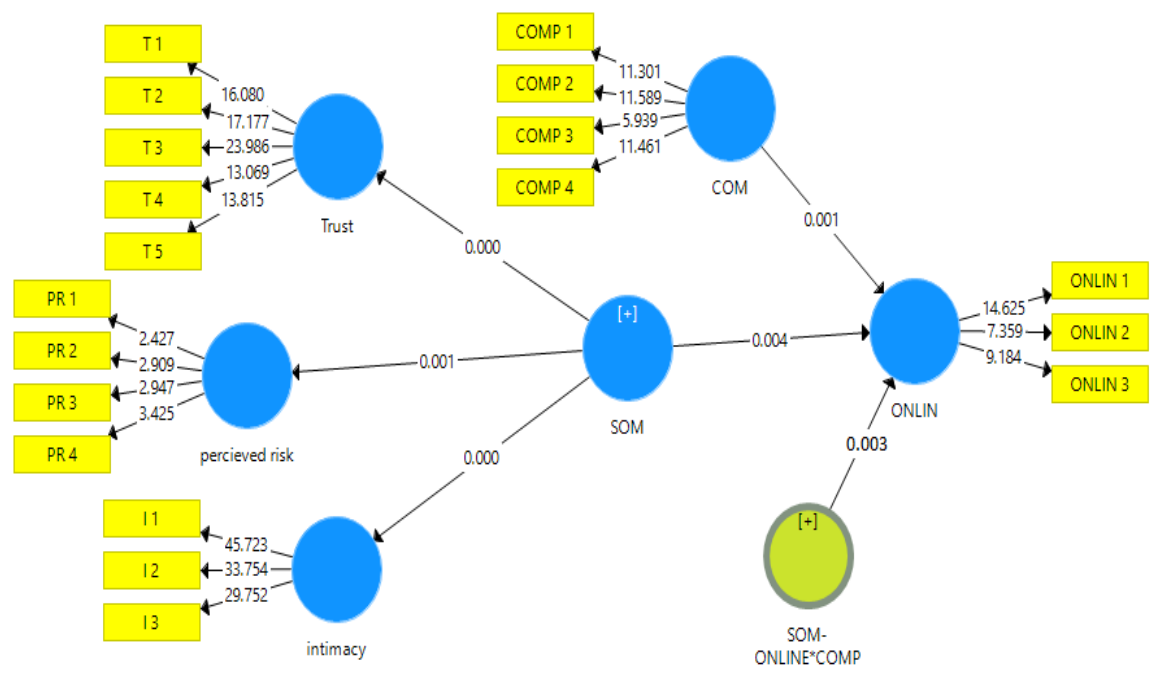

Fig. 3. Structural model

As displayed in Table 3; for online shopping intention (ONLIN), the achieved R2 value was 0.589 , and this denotes a $58.9 \%$ degree of variation in ONLIN. This result is in line with the suggested cut-off point of 0.19 by [49]. The construct is therefore clarified by its predictors. Further, the Q2 value associated with ONLIN was 0.280, which is significantly above the value of zero, affirming the relevance of the predictive model suggested [50]. The acceptableness of the model is therefore affirmed. Equally, the model showed predictive relevance of high level. As for the VIF values, there were recorded at 1.343 and 1.105, and in line with the suggestion of [46], the values are lower than 5 .

Table 3 and Figure 3 display a positive influence of social media (SOM) predictor on ONLIN, with the following values: $\beta=0.383$ and $p=0.000<0.05$. This implies that $\mathrm{H} 1$ is supported (SOM on ONLIN). Meanwhile, $\mathrm{H} 2$ relates to the moderating effect of social media on the relationship between P-IM and TI, and the obtained values are as follows: $\beta=0.117$ and $p=0.003<0.05$. As can be observed in Figure 4 , the lines are not parallel. The results show that social media fortifies the positive relationship between SOM and ONLIN, along with the change taking place in R2 (prior to entering the interaction effect of 0.581 - see Figure 1) and increased upon entering an interaction value of 0.589 (Figure 2). Further, the relationship between SOM and ONLIN is shown to be moderated, lending support to $\mathrm{H} 2$. 


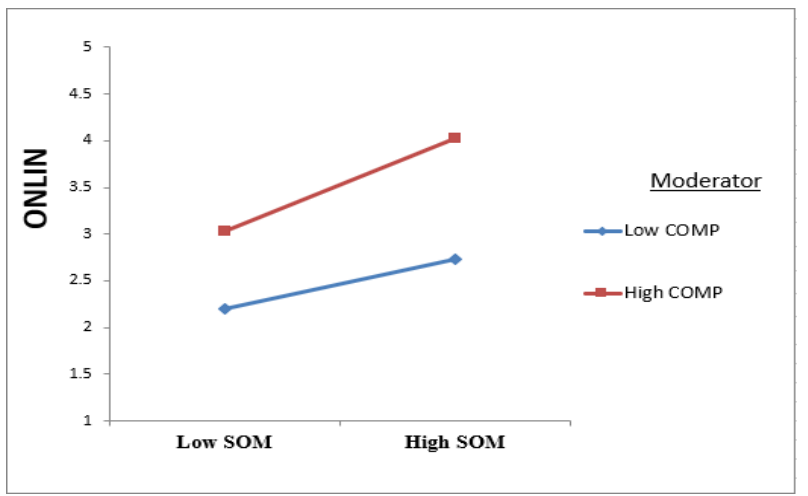

Fig. 4. Moderation Effect of COMP on the Relationship between SOM and ONLIN

Table 3. Structural model

\begin{tabular}{|l|c|c|c|c|c|c|c|}
\hline \multicolumn{1}{|c|}{ Path } & S. $\boldsymbol{\beta}$ & S. D & $\mathbf{R}^{\mathbf{2}}$ & $\mathbf{Q}^{\mathbf{2}}$ & VIF & T-value & P Values \\
\hline H1- SOM > ONLIN & 0.383 & 0.134 & 0.589 & 0.280 & 1.343 & 2.858 & 0.000 \\
\hline H2- SOM ONLIN*COMP & 0.117 & 0.050 & & & 1.105 & 2.340 & 0.003 \\
\hline
\end{tabular}

\section{$5 \quad$ Conclusion and Future Studies}

Past researches on social media and online shopping intention [33] and [34] were focusing on the impact of social media on online shopping intention, and all of these studies reported a positive impact of social media on online shopping intention. The same finding was also reported in the present study, whereby Social media was found to greatly impact behavioral motivation through the establishment of a direct relationship with the customers of pharmacies, decreasing the perceived risk, and increasing customer trust, all of which will motivate them to purchase medical products using online platforms.

This study tested the moderating role of comprehensiveness on the relationship between social media and intention towards online shopping. The research variables were analyzed using PLS-SEM, and from the results, this study concluded the significant impact of comprehensiveness in increasing social media effectiveness. Further, this study found that comprehensiveness presents the consumer with a complete and adequate message through the owners and promoters of pharmacy. Comprehensiveness also provides the value needed, fulfils the needs of customer, while also providing adequate breadth and width. Furthermore, comprehensiveness promotes trust of customer towards e-business platform. In turn, this will enthuse them to perform online shopping. In other words, comprehensiveness solidifies the positive relationship between social media and online shopping intention.

This study illustrates the effective use of TAM as in [51] and TPB as in [52]. Further, this study found that the intent towards online shopping can be increased by increasing intimacy, decreasing the perceived risk, establishing trust via the provision of adequate 
messages, and by providing clarification of the required value to the customers in order to motivate them to make purchases via the online platforms.

A number of recommendations can be considered based on the outcomes of this study. Firstly, as this study was carried out in Jordan, similar study should be carried out in other Middle East countries. Secondly, aside from customers of pharmacies, future studies should be focusing on other sectors such as restaurants and department stores. Thirdly, aside from using comprehensiveness as moderator to the relationship between social media and intention to online shopping, other constructs such as influencer characters can also be used as moderator to the same relationship.

\section{References}

[1] Internet World Stats. (2019), "World Internet Usage and Population Statistics", available at www.internetworldstats.com/stats.htm (accessed 12 Jan 2019).

[2] Statista (2019), "E-commerce worldwide. Statistics and facts", available at www.statista.com/topics/871/onlineshopping/ (accessed 12 Jan 2019).

[3] Paynter, J., \& Lim, J. (2001). Drivers and impediments to e-commerce in Malaysia. Malaysian Journal of Library \& Information Science, 6(2), 1-19.

[4] Bourlakis, M., Papagiannidis, S., \& Fox, H. (2008). E-consumer behaviour: Past, present and future trajectories of an evolving retail revolution. International Journal of E-Business Research (IJEBR), 4(3), 64-76. https://doi.org/10.4018/jebr.2008070104

[5] Rawashdeh, G., Bin Mamat, R., Bakar, Z. B. A., \& Rahim, N. H. A. (2019). Comparative between optimization feature selection by using classifiers algorithms on spam email. International Journal of Electrical \& Computer Engineering (2088-8708), 9. https://doi.org/ $\underline{10.11591 / i j e c e . v 9 i 6 . p p 5479-5485}$

[6] Masoud, E. Y. (2013). The effect of perceived risk on online shopping in Jordan. European Journal of Business and Management, 5(6), 76-87.

[7] Aldhmour, F., \& Sarayrah, I. (2016). An investigation of factors influencing consumers' intention to use online shopping: an empirical study in south of jordan. The Journal of Internet Banking and Commerce, 21(2).

[8] Alsoud, M. A. S., \& bin Lebai Othman, I. (2018). The Determinant of Online Shopping Intention in Jordan: A Review and Suggestions for Future Research. International Journal of Academic Research in Business and Social Sciences, 8(8). https://doi.org/10.6007/ ijarbss/v8-i8/4507

[9] AL-Shukri, H. K. H. (2019). Factors Influencing Online Shopping Intention: A study among online shoppers in Oman. INTERNATIONAL JOURNAL OF ACADEMIC RESEARCH IN BUSINESS AND SOCIAL SCIENCES, 9(3). https://doi.org/10.6007/ijarbss/v9-i3/5736

[10] Al-dweeri, R. M., Obeidat, Z. M., Al-dwiry, M. A., Alshurideh, M. T., \& Alhorani, A. M. (2017). The impact of e-service quality and e-loyalty on online shopping: moderating effect of e-satisfaction and e-trust. International Journal of Marketing Studies, 9(2), 92. https://doi.org/10.5539/ijms.v9n2p92

[11] Jordan, G., Leskovar, R., \& Marič, M. (2018). Impact of fear of identity theft and perceived risk on online purchase intention. Organizacija, 51(2), 146-155. https://doi.org/10.2478/ orga-2018-0007

[12] Erkan, I., \& Evans, C. (2018). Social media or shopping websites? The influence of eWOM on consumers' online purchase intentions. Journal of Marketing Communications, 24(6), 617-632. https://doi.org/10.1080/13527266.2016.1184706 
[13] Cheung, C. M., Lee, M. K., \& Rabjohn, N. (2008). The impact of electronic word-of-mouth: The adoption of online opinions in online customer communities. Internet Research: Electronic Networking Applications and Policy, 18(3), 229-247. https://doi.org/10.1108/ 10662240810883290

[14] Dai, M., \& Van Hove, L. (2017). The impact of customer images on online purchase decisions: Evidence from a Chinese C2C Web site. First Monday, 22(10). https://doi.org/10.5210/fm.v22i10.7120

[15] Appel, G., Grewal, L., Hadi, R., \& Stephen, A. T. (2020). The future of social media in marketing. Journal of the Academy of Marketing Science, 48(1), 79-95. https://doi.org/10.1007/s11747-019-00695-1

[16] Jamali, H. R., Russell, B., Nicholas, D., \& Watkinson, A. (2014). Do online communities support research collaboration? Aslib Journal of Information Management. https://doi.org/10.1108/ajim-08-2013-0072

[17] Close, A. G., \& Kukar-Kinney, M. (2010). Beyond buying: Motivations behind consumers' online shopping cart use. Journal of Business Research, 63(9-10), 986-992. https://doi.org/10.1016/j.jbusres.2009.01.022

[18] Meskaran, F., Ismail, Z., \& Shanmugam, B. (2013). Online purchase intention: Effects of trust and security perception. Australian journal of basic and applied sciences, 7(6), 307315.

[19] Wei, N. T., Baharudin, A. S., Hussein, L. A., \& Hilmi, M. F. (2019). Factors Affecting User's Intention to Adopt Smart Home in Malaysia. International Journal of Interactive Mobile Technologies (iJIM), 13(12), 39-54. https://doi.org/10.3991/ijim.v13i12.11083

[20] Chu, K. K., \& Li, C. H. (2008). A study of the effect of risk-reduction strategies on purchase intentions in online shopping. IJEBM, 6(4), 213-226.

[21] Salisbury, W. D., Pearson, R. A., Pearson, A. W., \& Miller, D. W. (2001). Perceived security and World Wide Web purchase intention. Industrial Management \& Data Systems. https://doi.org/10.1108/02635570110390071

[22] Iqbal, S., Hunjra, A. I., \& Rehman, K. U. (2012). Consumer intention to shop online: B2C E-commerce in developing countries. Middle East Journal of Scientific Research, 12(4), 424-432.

[23] Schlosser, A. E., White, T. B., \& Lloyd, S. M. (2006). Converting web site visitors into buyers: how web site investment increases consumer trusting beliefs and online purchase intentions. Journal of marketing, 70(2), 133-148. https://doi.org/10.1509/jmkg.70. $\underline{2.133}$

[24] Ariffin, S. K., Mohan, T., \& Goh, Y. N. (2018). Influence of consumers' perceived risk on consumers' online purchase intention. Journal of Research in Interactive Marketing. https:// doi.org/10.1108/jrim-11-2017-0100

[25] Medina, I. G., \& Pereira, P. A. C. (2012). The Importance of Social Media for Commerce. A Case Study in Madeira (Portugal). International Journal of Interactive Mobile Technologies (iJIM), 6(1), 37-42. https://doi.org/10.3991/ijim.v6i1.1825

[26] Stephen, A. T., \& Toubia, O. (2010). Deriving value from social commerce networks. Journal of marketing research, 47(2), 215-228. https://doi.org/10.1509/jmkr.47.2.215

[27] Ogbonnaya, U. I. (2019). Adoption and Perceived Usefulness of Social Media by Pre-service Teachers in Nigeria. International Journal of Interactive Mobile Technologies (iJIM), 13(06), 52-67. https://doi.org/10.3991/ijim.v13i06.10299

[28] Zhang, K. Z., \& Benyoucef, M. (2016). Consumer behavior in social commerce: A literature review. Decision Support Systems, 86, 95-108. https://doi.org/10.1016/j.dss.2016. $\underline{04.001}$ 
[29] Goldfarb, A., McDevitt, R. C., Samila, S., \& Silverman, B. S. (2015). The effect of social interaction on economic transactions: Evidence from changes in two retail formats. Management Science, 61(12), 2963-2981. https://doi.org/10.1287/mnsc.2014.2030

[30] Liang, T. P., Ho, Y. T., Li, Y. W., \& Turban, E. (2011). What drives social commerce: The role of social support and relationship quality. International journal of electronic commerce, 16(2), 69-90. https://doi.org/10.2753/jec1086-4415160204

[31] Yin, X., Wang, H., Xia, Q., \& Gu, Q. (2019). How social interaction affects purchase intention in social commerce: A cultural perspective. Sustainability, 11(8), 2423e. https://doi.org $\underline{110.3390 / \mathrm{su} 1108+}$

[32] Sa'ait, N., Kanyan, A., \& Nazrin, M. F. (2016). The effect of e-WOM on customer purchase intention. International Academic Research Journal of Social Science, 2(1), 73-80.

[33] Jothi, C. A., \& Gaffoor, A. M. (2017). Impact of social media in online shopping. Journal on Management Studies, 3(3), 576-586.

[34] Hsu, C. L., Lin, J. C. C., \& Chiang, H. S. (2013). The effects of blogger recommendations on customers' online shopping intentions. Internet Research. https://doi.org/10.1108/ 10662241311295782

[35] Zimaitis, I., Degutis, M., \& Urbonavicius, S. (2020). Social Media Use and Paranoia: Factors That Matter in Online Shopping. Sustainability, 12(3), 904. https://doi.org/10.3390/ $\underline{\mathrm{su} 12030904}$

[36] Abdulahi, A., Samadi, B., \& Gharleghi, B. (2014). A study on the negative effects of social networking sites such as facebook among asia pacific university scholars in Malaysia. International Journal of Business and Social Science, 5(10).

[37] Leenes, R., Schallabock, J., \& Hansen, M. (2008). PRIME White Paper, third and final version, PRIME (Privacy and Identity Management for Europe). Retrieved from http://www.mendeley.com/research/prime-whitepaper-v2/

[38] Pütter, M. (2017). The impact of social media on consumer buying intention. Marketing, $3(1), 7-13$.

[39] Baron, R. M., \& Kenny, D. A. (1986). The moderator-mediator variable distinction in social psychological research: Conceptual, strategic, and statistical considerations. Journal of personality and social psychology, 51(6), 1173. https://doi.org/10.1037/0022-3514.51.6.1173

[40] Bibi, P. A. L. W. A. S. H. A., Pangil, F., \& Johari, J. (2016). HRM practices and employees' retention: The Moderating Role of Work Environment. European Academic Research, III, $12,12994-13015$.

[41] Al-Gasawneh, J., \& Al-Adamat, A. (2020). The relationship between perceived destination image, social media interaction and travel intentions relating to Neom city Academy of Strategic Management Journal, 19(2),529. retrieved from https://www.abacademies.org/articles/The-relationship-between-perceived-destination-image-social-media-interaction-andtravel-intentions-relating-to-NEOM-city-1939-6104-19-2-529.pdf https://doi.org/10.1080/02508281.2020.1796341

[42] Green, S. B. (1991). How many subjects does it take to do a regression analysis. Multivariate Behavioral Research, 26(3), 499-510. https://doi.org/10.1207/s15327906mbr2603 7

[43] Gefen, D., Rigdon, E. E., \& Straub, D. (2011). Editor's comments: An update and extension to SEM guidelines for administrative and social science research. Management Information Systems Quarterly, 35(2), iii-xiv. https://doi.org/10.2307/23044042

[44] Hair, J. F., Black, W. C., Babin, J., \& Anderson, R. E. (2010). Multivariate data analysis (7th ed.). Upper Saddle River.

[45] Hair Jr, J. F., Sarstedt, M., Ringle, C. M., \& Gudergan, S. P. (2017). Advanced issues in partial least squares structural equation modeling. saGe publications. https://doi.org/ $\underline{10.1007 / 978-3-319-05542-8 \_15-1}$ 
[46] Hair Jr, J. F., Hult, G. T. M., Ringle, C., \& Sarstedt, M. (2016). A primer on partial least squares structural equation modeling (PLS-SEM). Sage publications. https://doi.org/ 10.3926/oss.37

[47] Becker, Jan-Michael, Kristina Klein, and Martin Wetzels. "Hierarchical latent variable models in PLS-SEM: guidelines for using reflective-formative type models." Long Range Planning 45.5-6 (2012): 359-394. https://doi.org/10.1016/j.lrp.2012.10.001

[48] Henseler, J., Ringle, C. M., \& Sarstedt, M. (2015). A new criterion for assessing discriminant validity in variance-based structural equation modeling. Journal of the academy of marketing science, 43(1), 115-135. https://doi.org/10.1007/s11747-014-0403-8

[49] Chin, W. W. (1998). Commentary: Issues and opinion on structural equation modelling.

[50] Chin, W. W. (2010). How to write up and report PLS analyses. In Handbook of partial least squares (pp. 655-690). Springer, Berlin, Heidelberg https://doi.org/10.1007/978-3-540$\underline{32827-8 \_29}$

[51] López-Nicolás, C., Molina-Castillo, F. J., \& Bouwman, H. (2008). An assessment of advanced mobile services acceptance: Contributions from TAM and diffusion theory models. Information \& Management, 45(6), 359-364. https://doi.org/10.1016/j.im.2008.05. 001

[52] Ajzen, I. (2011). The theory of planned behaviour, reactions and reflections.

\section{$7 \quad$ Authors}

Dr. Jassim is an assistant professor at Applied science private university (ASU), Jordan, also he was a trainer and lecturer with many international academies and smart PLS analysis expert. Email: jassemghasawneh@yahoo.com

Prof. Mahmoud Hussein Al-Wadi Vice-President of the Middle East University and Dean of Business College, former President of Zarqa University, former senior consultant of quality assurance at King Saud University, Quality consultant at the quality assurance Council - Arab Universities Union. dean-business@meu.edu.jo Email: Mwadi57@yahoo.com

Dr. Belal Mahmoud AL Wadi assistant professor, senior consultant of learning and development at LEVENBERT®, CEO of the Jordanian society for entrepreneurship, former lecturer at Imam Abdulrahman Bin Faisal University. Email: Belal.alwadi@yahoo.com

Bandar Ersan Alown is a Ph.D student at the University Sultan Zainal Abidin (UnisZA), and research assistant Email: bandaraloun@gmail.com

Dr. Nawras M Nuseirat, is with Applied Science Private University (ASU), Jordan. Email: $\underline{n}$ nserat@asu.edu.jo

Article submitted 2020-05-10. Resubmitted 2020-06-17. Final acceptance 2020-05-26. Final version published as submitted by the authors. 